\section{ELECTRICITY IN HOSPITALS.}$$
\text { BY EMTLE थUARIN }
$$

Among the manifold purposes for which electricity is capable of being employed, its applications to therapeutics are the most curious, and a number of them a.re doubtless

known to our

readers. How ever this may be, we think it will $\mathrm{p} \mathrm{rove}$ none the less interesting to describe $\mathrm{th}$ e electric apparatus w h i c h hospitals $\mathrm{n}$ ow have at their disposal.

The description $t h$ a t we propose to give is that of the a p par a $\mathrm{us}$ which has been furnished quite recently to a hospital of London by Messrs. Lem mon \& Co., of that city.

Among the principal of such apparatus we may menticn those employed for the reatment of neurasthenia rheumatism, anæmia, and pulmonary tuberculosis; a LortetGenoud lamp, a Finsen-Reyn lamp, an improved Finsen apparatus, a Roentgen apparatus, a Wimshurst machine, etc. The various instruments are placed in the upper-story rooms of one of the buildings. They are supplied by two groups of generat ors of electricity, that is to say, by two groups each consisting of a steam motor that actuates an electric generator.

These generators give a con tinuous current and send it to a distributing board provided with commutators, etc., in order to permit of distributing the current among the different experi. mental rooms.

For the treatment of arthritis, rheumatism, anæmia, and neurasthenia use has been successfully made of high-tension currents, which are also efficaciously employed for pulmonary tuberculosis in certain stages. These currents are produced by means of an induction coil, with a special mercury interrupter. This latter is actuated by a small motor that receives a c on tin uous current from the line wire. A continuous current is likewise sent through $\mathrm{th} \mathrm{e}$ intermed i $\mathrm{u} \mathrm{m}$ of the interrupter to the primary of the c o i l, w h i c h thus receives very short emissions that succeed $0 \mathrm{n}$ e another very rapidly, and, through induction, produce a 1 te r n ating currents in the secondary of the coil. The rapidity of the oscillations is increased b y connecting, as in wireless telegraphy, the electrodes between which the sparks jump with the armatures of a battery of Leyden jars. The tension thus obtained is enormous and the discharges are very strong. Nevertheless they are applied to the subject to be treated, without any danger, either in the form, of general or partial electrification.

The French Lortet-Genoud lamp, which the hospital has more or less modified, is applied to the treatment of lupus, that repugnant disease of which electricity

has cured so many persons, many persons, treatment o $\mathrm{f}$ We have all probably $\mathrm{h}$ a d a $\mathrm{n}$ opportunity of witnessing some of the ravages of these two. cutaneous affections. $\mathrm{Dis}$. eases of this kind, those of the skin, are e $x$ tremely painful, a n d those afflicted with them s o metimes present a horrible sight. In $t h$ is domain alone electricity has already earned o u r g r a titude, since, for such affections, i t furnishes one

Fig. 3.-Apparatus for Galvanic, Faradic, and Electrolytic Treatment. of the best

Fig. 2,-Finsen Apparatus.

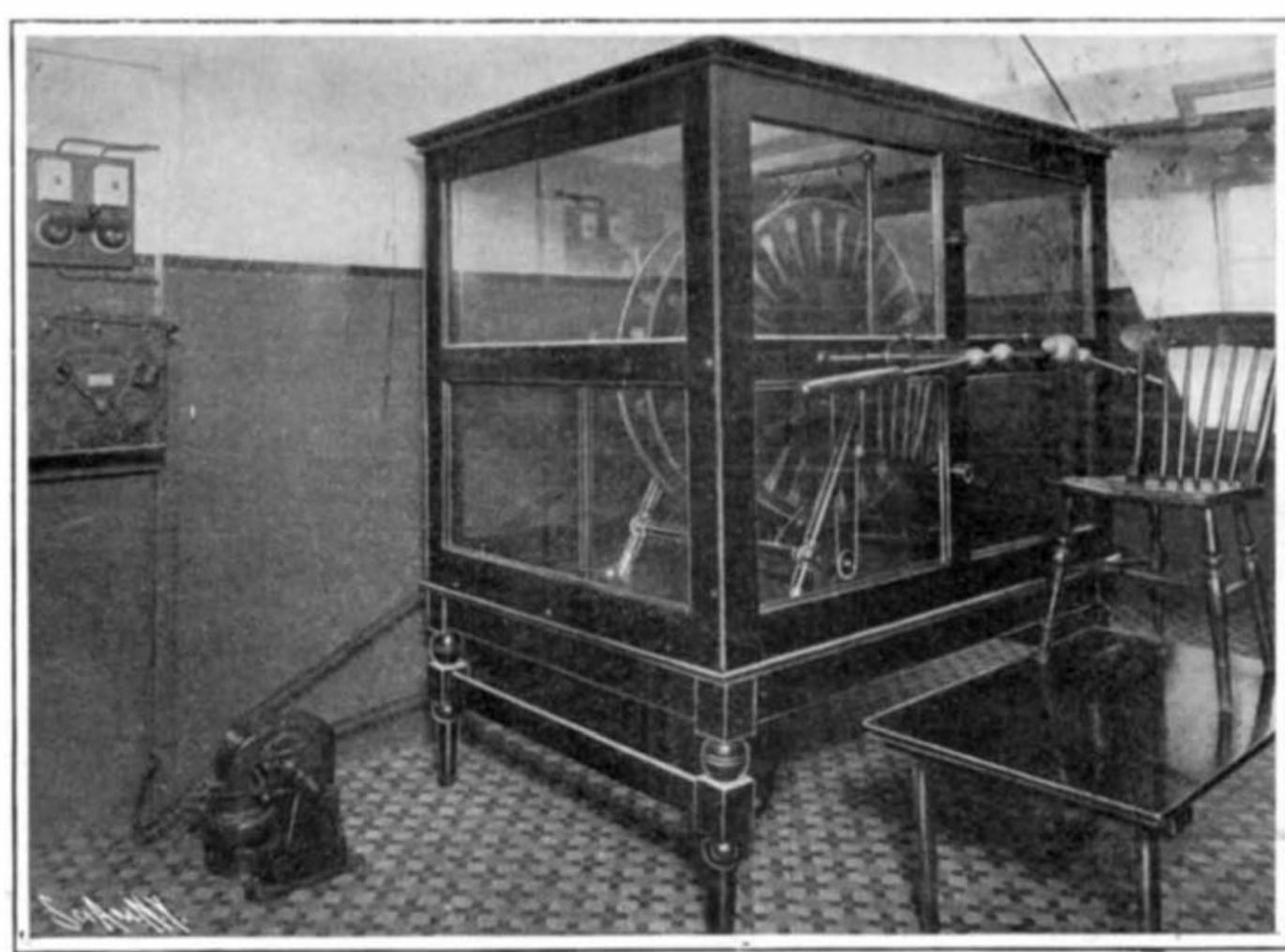

Fig. 5.-A Wimshurst Machine.

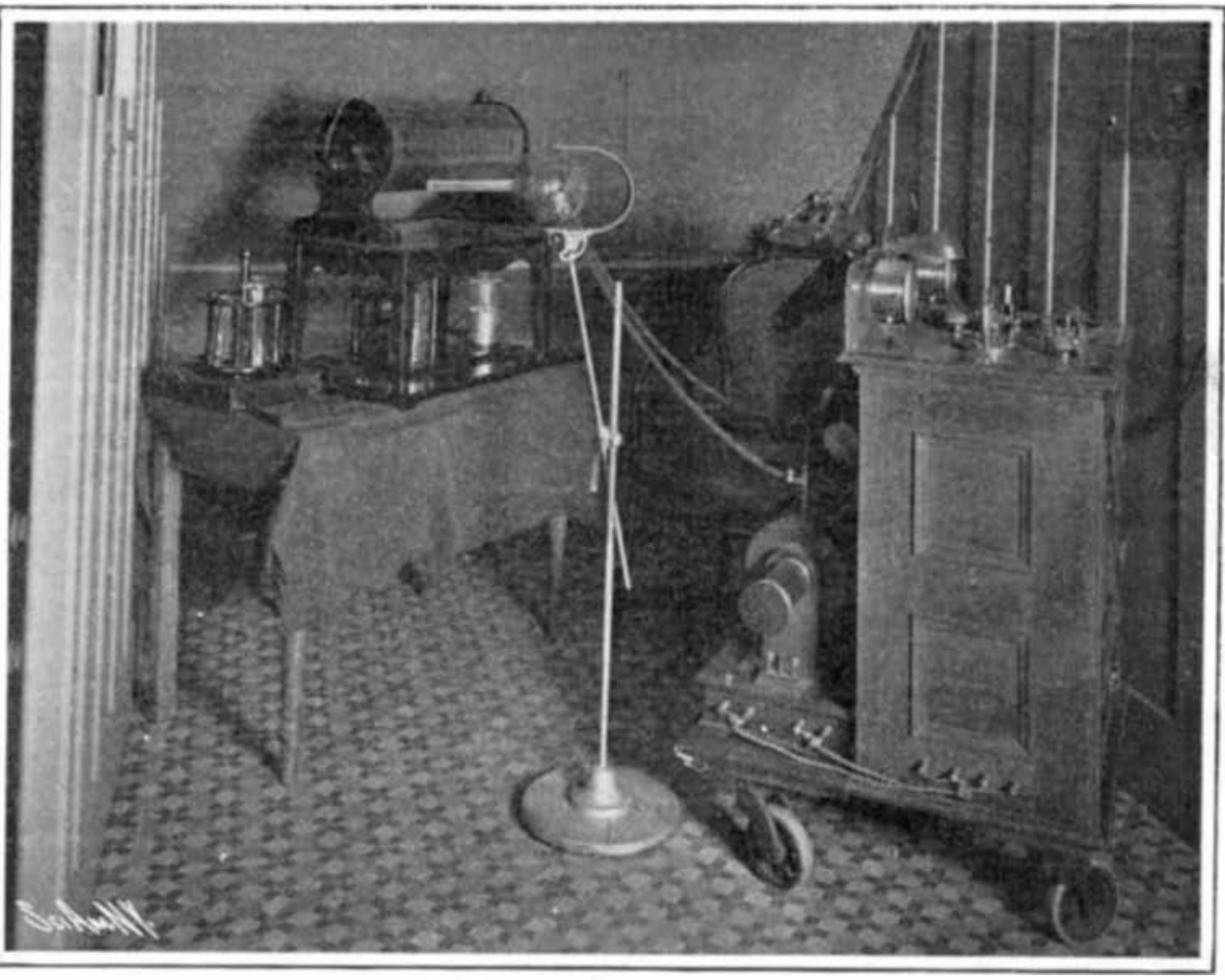

Fig. 4.-Roentgen Apparatus for Hospital Use.

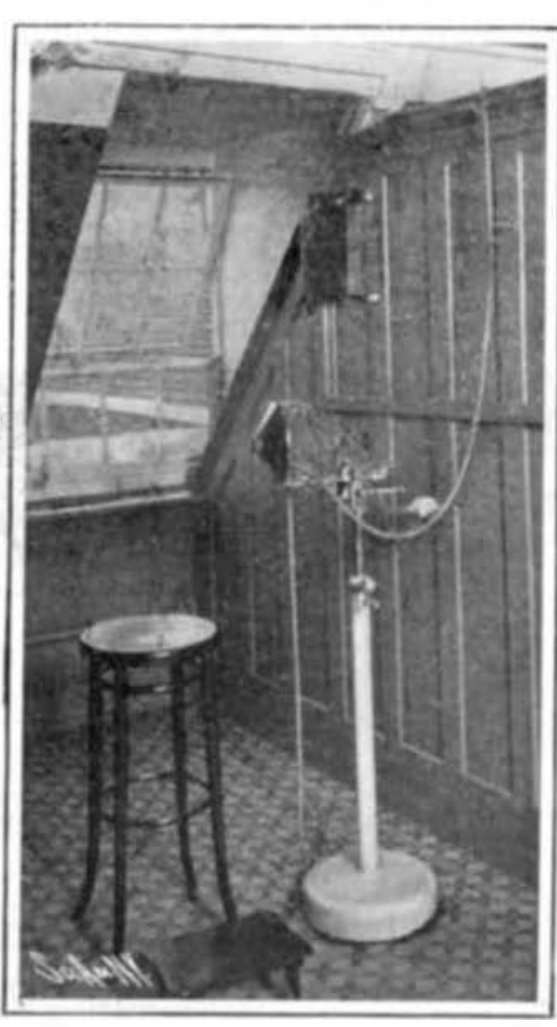

Fig. 1.--Lortet-Genoud Lamp. remedies hitherto discovered. The Lortet-Genoud apparatus mounted upon a heavy standard, and the rays of which are projected by means of a double screen provided with two central lenses of rock crystal upon the affected part of the patient. Between the walls of the lens support circulates the cold water mentione types to be tect the lenses and absorb the calorific rays. The pencil produced by the lamp consists, in fact, of calorific, luminous, and chemical rays, and the object to be attained is to disperse those that would have only an injurious effect, and allow of the passage of the chemical ones, which alone are capable of acting effcaciously.

The Finsen apparatus, of which the Finsen-Reyn is only a simplified modification, is likewise employed for the treatmen of lupus. It is therefore designed to permit of concentrating a to say, of ultra vi ole
ones, upon the affected part of the patient who lies upon a special couch.

In the sim u l t a n e ous treatment o several $p$ e $r$ sons, there is employed a $n$ i $\mathrm{mprov}$ e d model which i s especially c $\mathrm{h}$ aracterized by a bette utilization $o$ the luminous intensity of the lamp, the c o n sumption of which is notably reduced as com. pared with that of the former types. It c onsists (Fig. 2) in principle, of a 


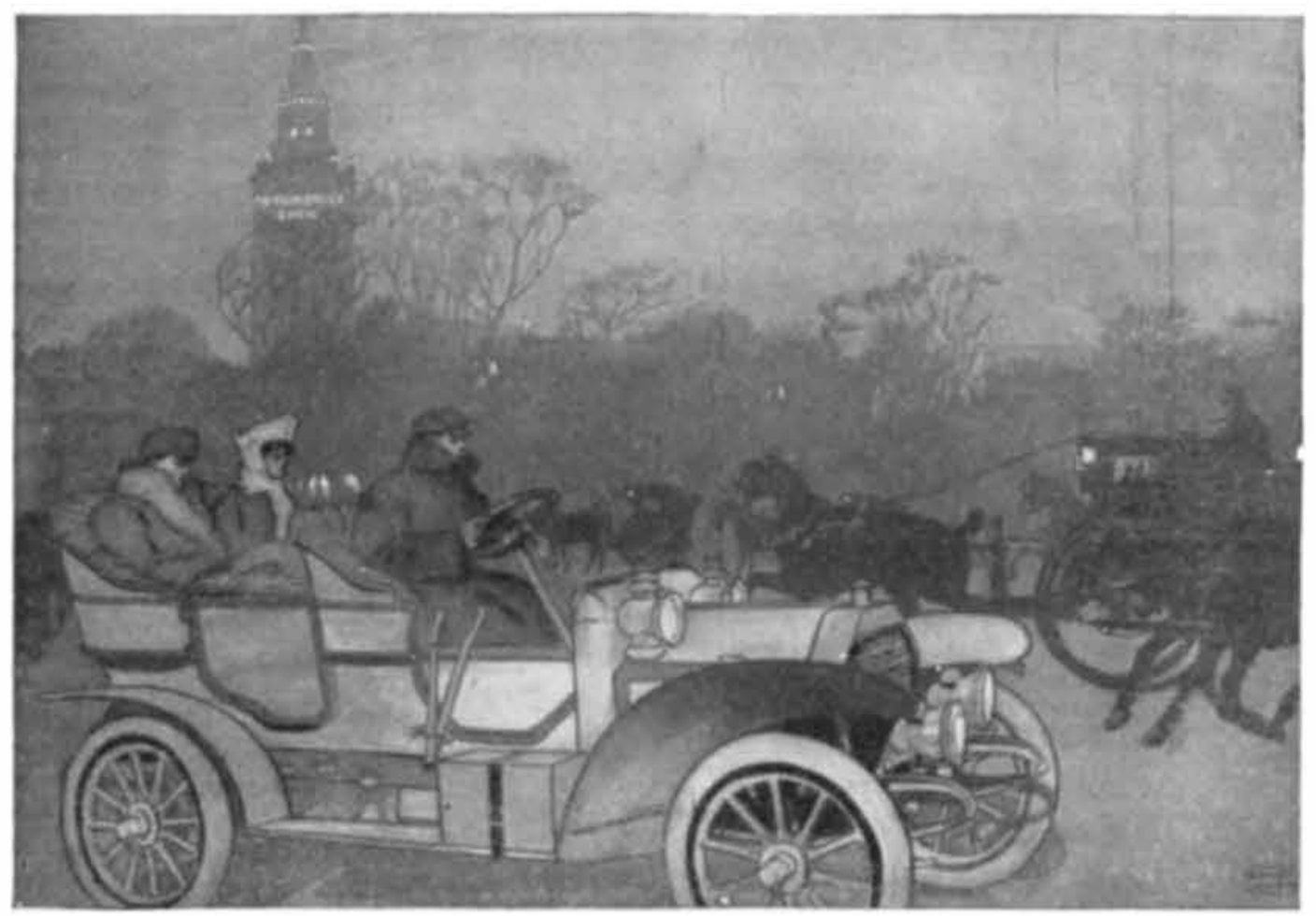

At the Madison Square Garden Automobile Show the

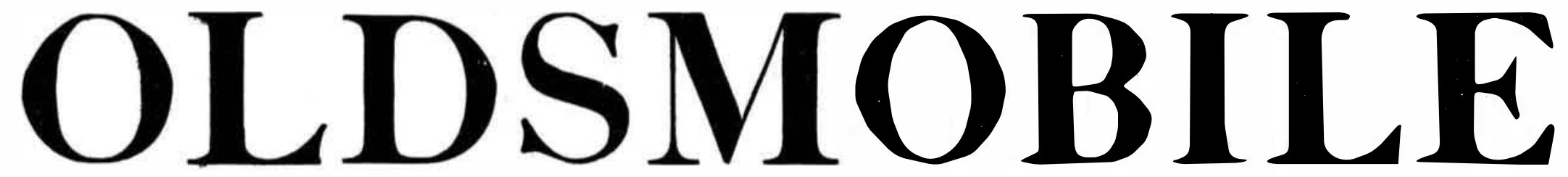

will center public interest in the Palace Touring Car and the Two-Cycle. Both of these cars emphasize the wonderful development of automobile construction in America. In style they set a swift pace for European manufacturers, and in performance they leave nothing to be desired in the way of speed, reserve power, easy riding qualities and general all-round completeness. Careful attention to the minutest detail is apparent in every line from the perfected motor to the adjustable lamp brackets.

If you, as a Possible Buyer of an Automobile (the Probable Buyer of an Oldsmobile after you have investigated) are too busy just at this time to let us give you a demonstration of our 1906 models, you can make a note, mental or otherwise, of the points. which mark the strong individuality of these cars - the superior quality and big value they represent on your money investment.

In general appearance the Palace Touring Car, Model S and The Two-Cycle, Model $\mathrm{L}$ are very similar, both conforming in design to the most approved European practice. The general lines of both cars are the same. Both have all the regulation outfit, sliding gear transmission, pressed steel frame, bevel gear drive, material of the best-everything that anyone has or wants to have and a number of features all our own.

The gasoline "motor" - the life center of the automobile-is merely a gasoline engine. We have built gasoline engines for 25 years, and we know this end of the business-know what not to build as well as what to build. The result of this experience is found in the motor equipment of every Oldsmobile.

The Four-Cylinder Motor of Model S is compact and free from complications; it is vertical, water-cooled, located under hood, and perfectly balanced. The bore is $4 / 4$-inch with $43 / 4$-inch stroke, and the actual horse power is from 26 to 28 . The weight of the car is 2,200 pounds. Wheel base 106 inches. Price $\$ 2,250$, with complete horn and lamp equipment.

The Two-Cycle Motor is likewise vertical, water-cooled and located under hood. Bore 5 inches, stroke 5 inches. THERE ARE ONLY THREE WORKING PARTS IN THE MOTOR ITSELF. If you don't know anything about gears, valves, guides and a few other things, you don't have to learn, because they are not there in The Two-Cycle. It is a $24 \mathrm{H}$. P. team without a harness. It's the only new thing in the last five years-a trial will convince you. Price $\$ 1,250$, with complete horn and lamp equipment:

We have a number of other good cars in our line-cars that have proved their staying qualities and worth through years of service. Complete information regarding any of our models can be obtained by making use of the coupon below.

\section{OLDS MOTOR WORKS, Lansing, Mich., U. S. A.}

Member Association of Licensed Automobile Manufacturers

\begin{tabular}{|c|c|c|c|}
\hline \multicolumn{4}{|c|}{$\begin{array}{l}\text { EUT COUPON HBRE } \\
\text { CATALOG COUPON }\end{array}$} \\
\hline \multicolumn{4}{|c|}{ 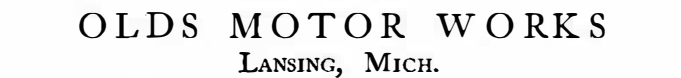 } \\
\hline \multicolumn{4}{|c|}{$\begin{array}{l}\text { Kindly send me information regarding cars } \\
\text { checked. I am interested. }\end{array}$} \\
\hline \multirow{2}{*}{\multicolumn{4}{|c|}{ 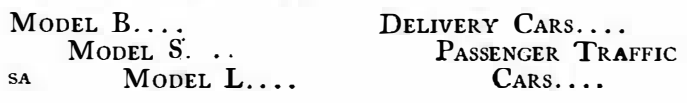 }} \\
\hline & & & \\
\hline \multicolumn{4}{|c|}{ Name } \\
\hline Addres & & & \\
\hline
\end{tabular}

\section{CALENDAR COUPON}

OLDS MOTOR WORKS Lansing, Mich.

Enclosed find Io cents, for which send your large Art Calendar (free from advertising and

suitable for framing ) for Igo6. Design by George Gibbs.

Name

Address
MOTOR TALK COUPON

OLDS MOTOR WORKS Lansing, Мich.

Enclosed find 25 cents, for zehich have Мотов TALK, a magazine devoted to automobiling, sent to me for I year. 
metallic cylinder suspended from a strong support and inclosing a lamp of great illuminating power. To this cylinder are secured telescopes, as well as tube for the circulation of water for cooling the telescopes and compressors. These telescopes are provided with rock crystal lenses. Between the two side ones there is a space filled with distilled water for the purpose of protecting the lenses against a high temperature and of eliminating the calorific rays. The last of these are absorbed at the other end by a column of distilled water about twelve inches in length comprised between the two lenses. The compressors consist of two rock crystal lenses between which water constantly circulates. They are applied closely to the skin and finally exclude every trace of all but the chemical rays.

Another operating room contains apparatus (Fig. 3) for experiments in galvanism, Faradization, and electrolysis. Here, too, are treated rheumatism and paralysis, and more particularly the affection known as writer's cramp.

The apparatus of this laboratory are connected with a tablet of polished marble which carries different measuring, regulating, and commutating instruments. These latter are principally a sensitive galvanometer of precision for measuring intensities; a reversing commutator for reversing the direction of the current; and a rheostat, otherwise called a regulatable resistance, of $10,000 \mathrm{ohms}$ divided into 56 degrees, that is to say, permitting of passing from 0 to $10,000 \mathrm{ohms}$ through 56 graduated values, and of thus obtaining a very precise regulation of the current, etc. A second group of very similar apparatus is placed in another room.

Roentgen rays are rendering valuable services in therapeutics, and the use of them in hospitals is now quite general. These rays, with whose strange powers every one is familiar, are, as is well known, obtained by producing electric discharges of great frequency in bulbs of highly rarefied air. Such discharges are produced by an induction coil of which the arrangement presents certain ana logies with that which we have briefly referred to above in connection with high-tension currents. The most characteristic part (Fig. 4) is the bulb, which is mounted upon a heavy standard surrounded by a transparent screen in the form of a globe, which in tercepts the $\mathrm{X}$-rays and protects the operator and patient against their dangerous effects. They are capable of reaching only the part of the body affected, since they are conducted by a tube of appropriate form fixed in an aperture with which the globe is provided. Such an arrangement presents different advantages.

Let us have a few words to say also of the Wimshurst machine (Fig. 5), one of the most remarkable of friction apparatus, and which is described in all works on electrostatics. This apparatus is employed with success in America for the treatment, under the name of Franklinization, of certain nervous affections, and especially of rheumatism. The use of it is spread ing likewise in England.

Finally, an apparatus which is no less interesting is the one that serves for massage and advantageously replaces massage by hand. This apparatus, of which the use is rapidly spreading, consists of an electric motor to the shaft of which is secured a large flexible cable, to the end of which is fastened a ball to which is communicated a vibratory motion of which the amplitude depends upon the regulation given it by means of a special arrangement that can be made to

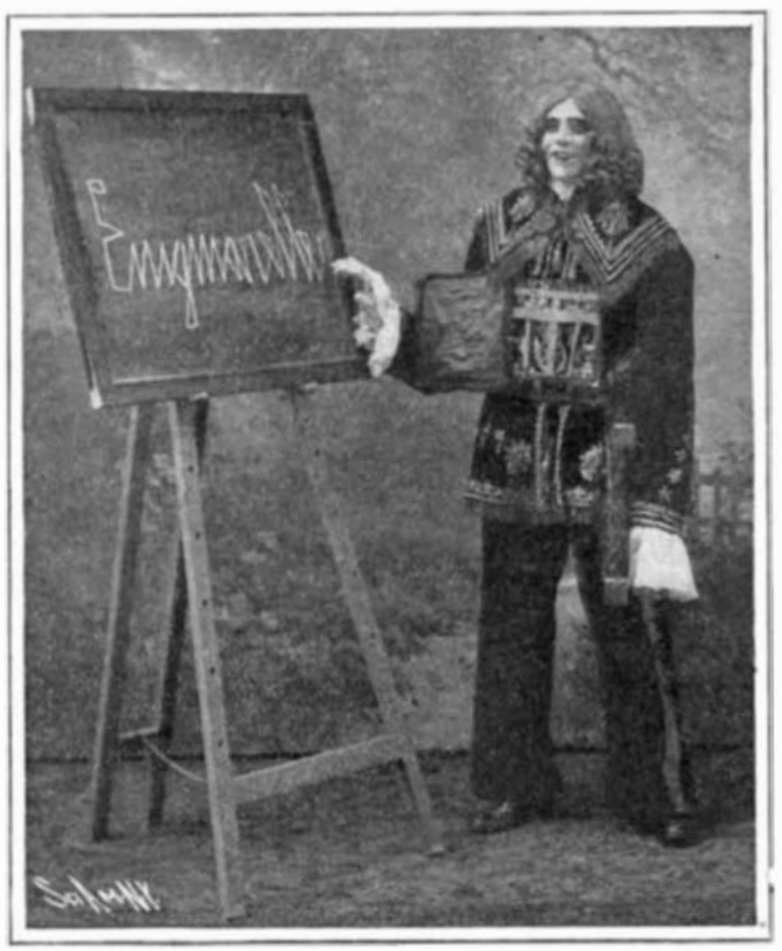

Automaton Writing, Chest Mechanism Exposed.

act during the operation. In this massage ball there are three screw holes into which may be introduced pieces of appropriate form for the local massage of employed for this is a special one, and is at the same employed for this is a special one, and is at the same
time a transformer which converts the continuous current furnished it by the line wire into an alternat ing one-a form of current that changes direction periodically and regularly with more or less rapidity. Another purpose for which the current is used is for the small electric lamps employed for the treat-

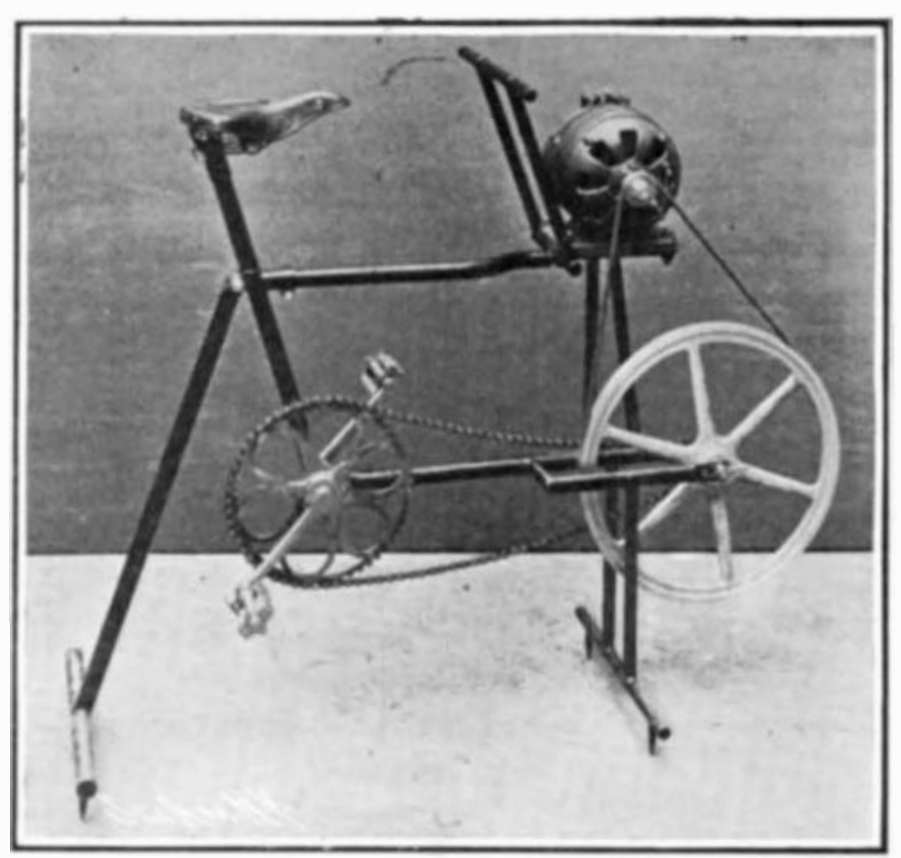
BICYCLE GENERATING STATION USED BY THE GERMAN ARMY'S
IRELESS TELEGRAPH CORPS IN THE SOUTH AFRICAN CAMPAIGN.

ment of laryngitis and analogous affections. The applications of electric energy to medicine will doubtless not stop here. Surgery will also find in the electric current a sure and valuable aid.

M. Leduc has already made known the anæsthetic effect of electric currents of high frequency, and has demonstrated that, under their influence, any animal falling upon the side sleeps a deep sleep that is interrupted neither by the prick of a needle or a burn by a hot iron.

It is doubtless known that MM. Didsbury and Regnier have constructed upon this principle an apparatus designed for the painless extraction of teeth. It has recently been found that the violet rays have the same effect.

The rays of an incandescent lamp, with a bulb of proper color surrounded by an appropriate shade, directed upon the eyes of a patient by means of a reflector of nickel-plated metal, produce at the end of two or three minutes an anæsthesia that suffices for the performance of unimportant operations.

These are facts of great interest that are multiplying every day and are constantly increasing the number of our methods of combating disease.

\section{A NEW TYPE OF PORTABLE WIRELESS TELEGRAPH STATION. \\ BY DR. ALFITI}

A very convenient type of portable wireless telegraph station was described by the author some time ago in these pages. The Wireless Telegraph Com-

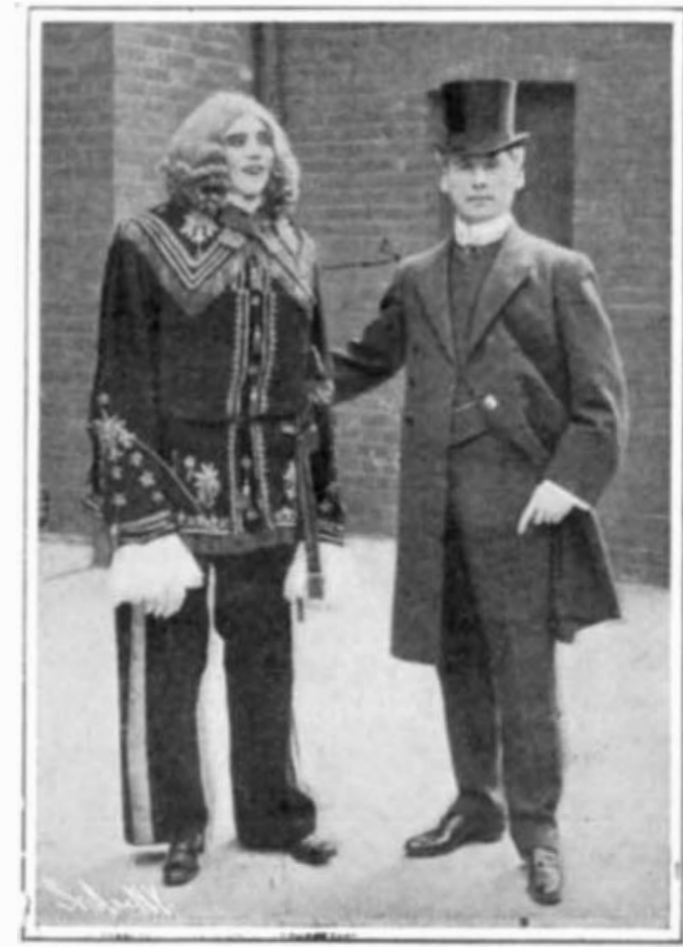

Introducing " Enigmarelle." pany, of Berlin, who were the constructors of these stations, have recently designed another type of such lightness as to require no carts in their transportation. Chiefly remarkable in this portable outfit are the means of generating energy. A bicycle dynamo is used. The constructive principle of the latter is simple. A small direct-current dynamo of about 100 watts output is fitted to a bicycle frame. The rider, if he may be so called, keeps the machine going by smart pedaling. From the sprocket of the bicycle frame the movement is transmitted to the dynamo by means of a belt, driving a specially-designed aluminium disk, the ratio of transmission being so designed as to have the dynamo produce sparks of 4 millimeters length in the induction coil, in normal operation. As the dynamo is located in front of the operator, the latter is in a position at any moment to supervise its uniform activity. The weight of the dynamo outfit is 30 kilogrammes ( 66 pounds). In the place of the de vice above described, a stationary motor cycle with a dynamo fitted on can be used. Apart from the dynamo a portable accumulator battery can be made use of to supply the energy required. The battery includes eight cells (16 volts), possessing a capacity of about 30 amperehours with a five hours' discharge. The admissible limit of discharging intensity is about 25 per cent greater than the energy necessary in normal working order. The cells are inclosed in an ebonite box, which is in turn divided into two compartments of 30 kilogrammes ( 66 pounds ) weight each.

\section{A CLEVER MECHANICAL AND ELECTRICAL} AUTOMATON.

An interesting, novel, and pseudo-scientific attraction has recently been entertaining Londo audiences at the Hippodrome variety theater. This is a cleverly-constructed figure which apparently walks and writes automatically. It is called "Enigmarelle," and is seemingly a mechanical and electrical combination. The figure stands exactly six feet in height, weighs 198 pounds, and is composed of 365 distinct and separate parts. As to composition, the feet are of iron, the lower limbs of steel and wood, while the arms are of steel and copper. The body is an insulated steel wire frame, cased with fiber and rawhide, while the head is of wax. The figure contains seven motors, three of which are spring and four electric. They are distributed in different parts of the body and are said to operate the various members assigned to them in the following manner:

The two most powerful motors, which are of specia design, propel the lower limbs, and cause the automaton to walk. A third operates the arms, a fourth the balance weights. of the spring motors, the first controls the head, the second acts as an auxiliary to the electric motors in the movement of the arms, while the third operates the wire bobbins, which wind and unwind with the ever-changing position of the weights.

There are fourteen dry storage battery cells of small capacity. They are of special design and constructed to serve a double purpose-not only to furnish power to the motors, but also to maintain the equilibrium of the figure. A little below where th hip joint would be on the left of the figure, is the terminal of a semi-circular vulcanite track, which passes up and over the upper part of the chest, de-

(Continued on page 57.)

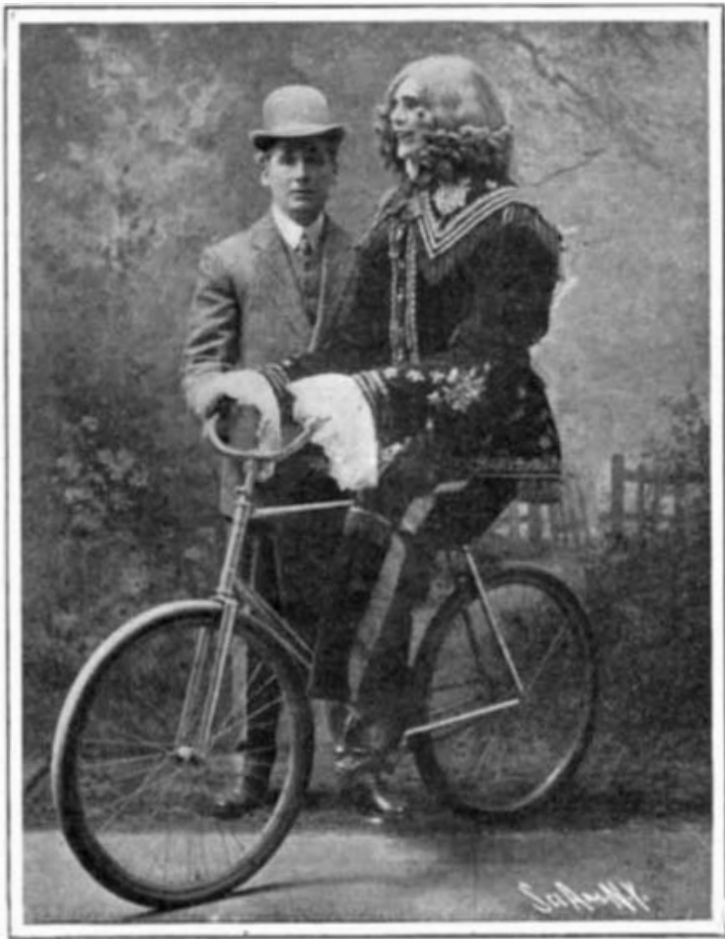

The Automaton Riding a Bicycle. 